Grundsatz durchaus geschickt in die Vorschriftenkommentierungen integriert - gewisse Ungenauigkeiten inbegriffen. So weist z.B. $\S 32$ Rdn. 1 am Ende darauf hin, dass der DSGVO-E in Art. 81 den nationalen Gesetzgebern für die Schaffung eigenständiger Beschäftigtendatenschutzregeln ausdrücklich Raum lasse. Einmal davon abgesehen, dass der Beschäftigtendatenschutz in Art. 82 erwähnt wird, gewährt der DSGVO-E den Mitgliedstaaten ausdrücklich nur eine Regelung „in den Grenzen dieser Verordnung“, überdies erhält die Kommission nach Art. 82 Abs. 3 die Ermächtigung zum Erlass delegierter Rechtsakten. Vor diesem Hintergrund sieht Art. 82 DSGVO also nicht unbedingt wesentlich weitergehenden Regelungsspielräume vor - was im Übrigen im weiteren EU-Gesetzgebungsverfahren verschiedentlich kritisiert wurde (nach gegenwärtigem Sachstand ist davon auszugehen, dass diese Kritik auch zumindest teilweise berücksichtigt wird).

Schwerpunkte der Neukommentierung liegen auf der Auftragsdatenverarbeitung, auf dem Scoring, Informationspflichten bei Datenverlusten und auf dem internationalen Datentransfer. Die Erläuterungen zu diesen gehörenden Vorschriften wurden von dem Rezensenten daher eingehender betrachtet. Die Kommentierung ist insoweit durchweg klar gegliedert und gibt zahlreiche Hinweise zur praktischen Umsetzung der gesetzlichen Bestimmungen. Mit anderen Worten ist der Gola/Schomerus nach wie vor ein echter Praktikerkommentar im positiven Sinne, auch wenn sich der Rezensent an oder anderen Stelle kritische Hinweise durchaus gewünscht hätte. Um nur einen der angedeuteten Schwerpunkte der Neubearbeitung aufzugreifen: Zu § 11 wird beispielsweise die Auffassung vertreten, dass die Pflicht des Auftraggebers zur sorgfältigen Auswahl eines konzernangehörigen Dienstleisters nicht ausgeschlossen ist, „, soweit dieser sich den Weisungen des Auftrag gebenden Unternehmens unterwirft" (§ $11 \mathrm{Rdn}$. 20). Diese Überlegungen sind rechtlich durchaus nachvollziehbar, gehen aber nicht auf das Problem ein, dass zumeist Konzernmuttergesellschaften die Rolle von Auftragnehmern übernehmen. In solchen Fallkonstellationen wird eine datenschutzrechtliche verantwortliche Konzerntochtergesellschaft als Auftraggeberin kaum in der Lage sein, der an konzernweit einheitlichen Standards interessierten Konzernmutter Weisungen zu erteilen. Was eine solche Sensibilisierung für derartige Problemlagen anbelangt, gibt es deutliche Unterschiede zwischen den einzelnen Verfassern. Diese kritische Anmerkung soll allerdings den hohen praktischen Nutzwert des Werkes nicht herabwürdigen. Als Fazit bleibt festzuhalten, dass "der Gola/Schomerus" auch in dieser Auflage uneingeschränkt sein Geld wert ist.

\section{Christoph Schnabel}

Müller, Lucien: Videoüberwachung in öffentlich zugänglichen Räumen - insbesondere zur Verhütung und Ahndung von Straftaten, Dike Verlag / Nomos, 376 S., 69,- $€$ 。

Das Werk betrifft zwar die Rechtslage nach schweizerischem Recht, ist aber trotzdem in vielerlei Hinsicht auch für Leser interessant, die sich mit der Entwicklung in Deutschland auseinandersetzen (müssen). Dies liegt nicht nur daran, dass Müller in erheblichem Umfang auf deutsche Literatur zurückgreift. Der Abschnitt über den Stand der Technik (S. 15 ff.) ist natürlich auf Deutschland übertragbar. Gleiches gilt

für dogmatisch interessante Frage, ob eine grundrechtliche Verpflichtung zur Videoüberwachung bestehen kann (S. 188 ff.). Bei der Prüfung der Verhältnismäßigkeit ist, wie in anderen Arbeiten auch, die Geeignetheit die spannendste Frage (S. 241 ff.). Die Ergebnisse sind, ebenfalls wie in anderen Arbeiten, nicht eindeutig.

Insgesamt elf Grundrechte und Rechtsgüter identifiziert Müller, die durch die Videoüberwachung beeinträchtigt werden könnten (S. $97 \mathrm{ff}$.). Dieser beeindruckenden Zahl stehen allerdings die doch eher knapp bemessenen 80 Seiten gegenüber, auf denen alle elf Rechtsgüter abgehandelt werden, so dass es bei einigen nur für eher oberflächliche Ausführungen reicht.

Aus deutscher Sicht nicht erheblich sind die Ausführungen dazu, ob die Videoüberwachung Personenbezug hat (S. 42 ff.), da mit $\S$ 6b BDSG eine Spezialregelung besteht. Ähnliches gilt für die Kompetenzdebatte zum Erlass polizeirechtlicher Videoüberwachungsvorschriften, die Müller, natürlich an der Schweizer Verfassung diskutiert (S. 195 ff.).

Die Arbeit endet mit einem Exkurs zum Einsatz der Videoüberwachung durch Private (S. 307 ff.). Insgesamt stellt die Arbeit einen guten Überblick über die verschiedenen Probleme beim Einsatz von Videoüberwachung in öffentliche zugänglichen Räumen dar, auch wenn die Ausführungen bisweilen etwas kurz geraten. Zu kritisieren bleibt lediglich der Hang Müllers, Fußnoten so umfangreich zu gestalten, dass sie selbst kleine Aufsätze darstellen. Davon abgesehen vermag seine Arbeit die an sie gestellten Ansprüche jedoch zu erfüllen. 